\title{
Variations of Cup-to-Disc Ratio in Children
}

\author{
Sherif Ahmed Kamel Amer ${ }^{1}$, Mohamed Yasser Sayed Saif ${ }^{{ }^{*}}$, Ahmed Tamer Sayed Saif ${ }^{2}$, \\ Passant Sayed Saif ${ }^{3}$
}

${ }^{1}$ Ophthalmology Department in Beni-Suef University, Beni-Suef, Egypt; ${ }^{2}$ Ophthalmology Department in Fayoum University, Al Fayoum, Egypt; ${ }^{3}$ Ophthalmology Department in Misr University for Science and Technology, 6th of October City, Egypt. Email: *ysaif@med.bsu.edu.eg

Received December $14^{\text {th }}, 2013$; revised January $14^{\text {th }}, 2014$; accepted January $24^{\text {th }}, 2014$

Copyright (C) 2014 Sherif Ahmed Kamel Amer et al. This is an open access article distributed under the Creative Commons Attribution License, which permits unrestricted use, distribution, and reproduction in any medium, provided the original work is properly cited. In accordance of the Creative Commons Attribution License all Copyrights (C 2014 are reserved for SCIRP and the owner of the intellectual property Sherif Ahmed Kamel Amer et al. All Copyright (C) 2014 are guarded by law and by SCIRP as a guardian.

\begin{abstract}
Purpose: The aim of this study is early detection of increased cup to disc ratio and a survey study of cup-disc ratio in Egyptian children age group less than 15 years. Methods: Three hundred and eighty-two (382) children were enrolled in this study. They were classified into three age groups; infants' Group (1) from 0 - 2 years, preschool Group (2) from 2 - 6 years and school children Group (3) from 6 - 15 years old. C/D ratio was measured for each child. Results: In Group (1), normal C/D ratio ranged from 0 to 0.1 . The C/D ratio $>0.3$ or a binocular difference of $>0.2$ could be regarded as one of the criteria of newborn glaucoma. Group (2): the normal ratio ranged from $0.1-0.2$. Group (3): the normal ratio ranged from $0.2-0.3$. The highest ratio 0.7 was found in two eyes. An asymmetry of 0.2 or more in the $C / D$ ratios of the eyes was found in $4.8 \%$ of the children. Conclusion: C/D ratio $>0.3$ and asymmetry of 0.2 is suggestive of glaucoma especially in infants of lower age group.
\end{abstract}

\section{KEYWORDS}

\section{Cup to Disc Ratio; Children}

\section{Introductio}

In adults, large optic disc cups are often a sign of glaucoma. Children, however, show a lower prevalence of glaucoma than adults [1], but may present with optic disc cupping of nonglaucomatous origin. Large disc cups in children may be diagnosed as physiologic large cups or may be associated with prematurity and periventricular leukomalacia [2].

To date, little is known about the morphology of optic discs in premature infants. However, optic disc morphology and optic nerve development are two factors that potentially influence visual function in infants [3].

Children with large optic disc cups often present a clinical dilemma on initial examination, as tests to rule out glaucoma, including intraocular pressure measurement and formal visual field analysis, can be difficult within the pediatric age group [4].

Pediatric glaucoma includes a wide variety of conditions ranging from primary congenital glaucoma since ${ }^{*}$ Corresponding author. birth to developmental glaucoma associated with other diseases and acquired glaucoma secondary to multiple causes. Depending on the age of the patient, it presents with particular features and circumstances that need to be taken into account and frequently require surgical intervention [5].

This study is designed to detect changes in the cup to disc (C/D) ratio as a survey study of C/D ratio in Egyptian children of age group less than 15 years as a trial to understand the incidence of pediatric glaucoma in such age groups.

\section{Patients and Methods}

This study included 382 children, collected from the ophthalmology outpatient clinics in Beni-Suef University Hospital, Fayoum University hospital and Misr University hospital. Their age ranging from 0 - 15 years old and classified into three age groups; Group (1), infantile group: from 0 - 2, preschool children Group (2) with ages from $>2$ - 6 years and Group (3), school age children 
with ages ranged from $>6$ - 15 years.

Patients with diabetes mellitus, systemic disease as anemia, and patient known to have any serious eye disease were excluded from the study.

After approval of the ophthalmology department council and IRB in Beni-Suef University, consent was signed by the patient parents before including in the study.

All the patients were subjected to the following:

\section{A) Sheet of full medical history:}

- Personal history: name, age, sex, location, occupation and gestationhistory (prematurity may influence disc morphology) [6];

- Past history of serious illness as: diabetes, hypertension, liver diseases, immunosuppressive diseases or autoimmune diseases.

- Past medical history of:

1) Systemic medications as: steroids, immunosuppressive drugs, insulin, $\beta$-blockers, interferon, antihistaminics, chemotherapy or radiotherapy;

2) Local medications as: local steroids, antibiotics, $\beta$-blockers, local anesthetics, medications that are used daily by the patient (IOP lowering agents), decongestant and antihistaminics;

3) Ocular surgery as: cataract, glaucoma or retinal detachment;

4) Previous ocular diseases as: uvitis, autoimmune diseases (Steven-Johnson syndrome) or severe eye trauma.

B) Routine ophthalmologic examination to all the patients:

- Visual acuity assessment using Landolt "C" eye chart;

- Examination of anterior segment of the eye for exclusion of presence of any serious ocular disease;

- IOP measuring byapplanation tonometer;

- Measuring of C/D ratio using Volk +90 D. and indirect ophthalmoscope. The $\mathrm{C} / \mathrm{D}$ ratio was measured by 2 observers and the mean ratio was recorded in the data sheet.

C) Special investigations for suspected glaucoma cases:

- Visual field;

- OCT.

\section{Results}

The study included 382 patients; of them 182 were males and 200 females. The studied children were classified into three age groups. Group (1): 22 infants aged 0 - 2 years. Group (2): 87 preschool children aged $>2-6$ years. Group (3): 273 school children aged $>6$ - 15 years.

In Group (1), normal C/D ratio ranged from 0 to 0.1 . The C/D ratio $>0.3$ or a binocular difference of $>0.2$ could be regarded as one of the criteria of newborn glaucoma [7]. Group (2): the normal ratio ranged from 0.1 - 0.2. Group (3): the normal ratio ranged from 0.2 -

\section{3 (Figure 1).}

Data were collected, statistically analyzed and tabulated in the following Tables 1-4.

Table 2 shows different C/D ratios in each age group. It is observed that in Group (1), all infants showed normal $\mathrm{C} / \mathrm{D}$ ratio (i.e. $\mathrm{C} / \mathrm{D}$ equal to or less than 0.1 ). In Group (2), most of the preschool children, 78 (89.7\%), had normal $\mathrm{C} / \mathrm{D}$ ratios (i.e. $\mathrm{C} / \mathrm{D}$ less than 0.2 ) and 7 of them (8\%) had suspected abnormal $\mathrm{C} / \mathrm{D}$ ratio (i.e. $\mathrm{C} / \mathrm{D}=$ 0.3 ), this group showed two abnormal $\mathrm{C} / \mathrm{D}$ ratios, one was 0.4 and one was 0.5 (2.3\%). Group (3) showed 249 out of 273 children (71.3\%) normal C/D ratios, 19 (6.96\%) had suspected abnormal C/D ratios, while 5 children (1.83\%) had abnormal C/D ratios (Table 3 ). The 5 abnormal children were two had C/D ratio 0.4 , while $\mathrm{C} / \mathrm{D}$ ratios of $0.5,0.6$ and 0.7 were found in one child each. So the highest C/D ratio found was one case had 0.7 in Group (3).

Asymmetry of C/D ratio between both eyes equal to or more than 0.2 was considered abnormal. All children in Group (1) showed asymmetry < 0.1, while Group (2) showed 4 children out of 87 (4.6\%) had asymmetry $>0.2$ and Group (3) showed 14 children out of 273 had asymmetry $(\mathrm{P}<0.05)$ (Figure 2$)$.

\section{Discussion}

The cup/disc (C/D) ratio was introduced by Armaly and Sayeghi [8] as a standardised method to evaluate the optic nerve and to communicate the results. It has been shown that the larger the $\mathrm{C} / \mathrm{D}$ ratio, the more severe the field damage is likely to be [9].

However, the $\mathrm{C} / \mathrm{D}$ ratio does not take into consideration the diameter of the optic disc, nor does it directly describe focal changes in the neuroretinal rim. It has been long recognised that focal rim loss, particularly at the vertical poles of the disc are characteristic of glaucoma [10].

Several investigators have pointed out that small discs have fewer nerve fibres and smaller $\mathrm{C} / \mathrm{D}$ ratios than do larger discs [11].

Children with large optic nerve head cups often pose diagnostic difficulty due to concern over possible glaucoma [12]. They report that children with large cup-todisc ratios have evidence of reduced/thinner RNFL and macular volume versus children with smaller cup-to-disc ratios, as assessed by OCT.

This study was done on 382 children attended ophthalmology outpatient clinic in Beni-Suef University hospital, age ranging from (0 - 15) years, 5.7\% of them in infantile stage ranged from ( 0 - 2 years) constitutes Group (1), 22.8\% of them in preschool stage, ranged from (2 - 6) years, constitutes Group (2) and 71.5\% of them in the school stage, ranged from (6 - 15) years, 


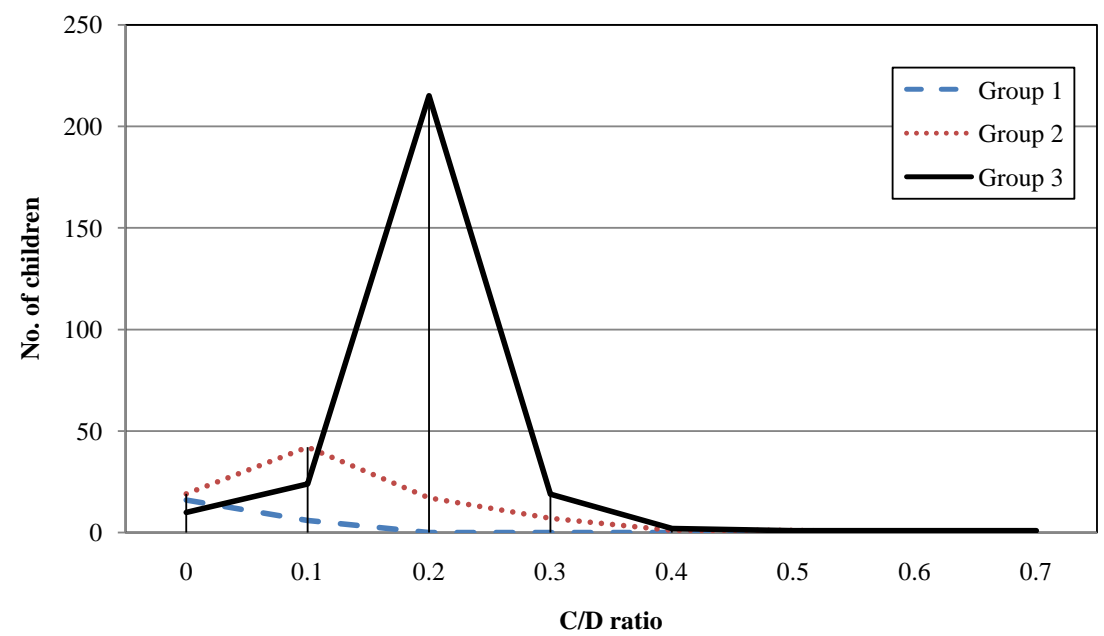

Figure 1. Incidence of $C / D$ ratio in the three studied groups.

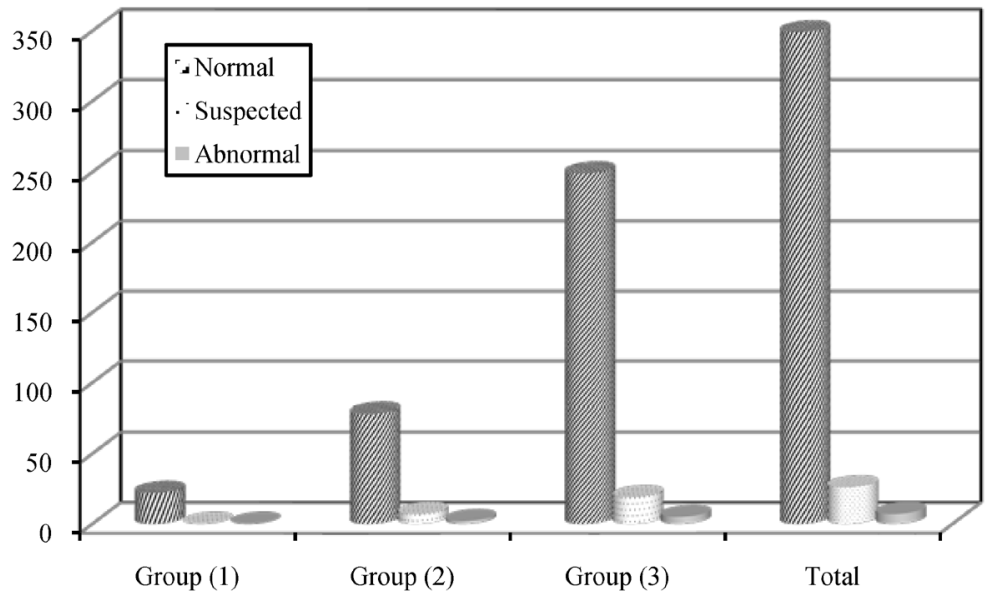

Figure 2. Identification of C/D ratio in the three studied groups.

Table 1. Sex distribution of the studied groups.

\begin{tabular}{cccccccc}
\hline \multirow{2}{*}{ Groups } & \multirow{2}{*}{ Age range (years) } & \multicolumn{2}{c}{ Males } & \multicolumn{2}{c}{ Females } & \multicolumn{3}{c}{ Total } \\
\cline { 3 - 8 } & & No. & $\%$ & No. & $\%$ & No. & $\%$ \\
\hline Group (1) & $\leq 2$ & 10 & 2.62 & 12 & 3.14 & 22 & 5.7 \\
Group (2) & $>2-6$ & 42 & 10.9 & 45 & 11.8 & 87 & 22.8 \\
Group (3) & $>6-15$ & 130 & 34.1 & 143 & 37.4 & 273 & 71.5 \\
Total & $0-15$ & 182 & 47.6 & 200 & 52.4 & 382 & 100 \\
\hline
\end{tabular}

Table 2. Distribution of $\mathbf{C} / \mathrm{D}$ ratio in the three studied groups.

\begin{tabular}{ccccccccc}
\hline \multirow{2}{*}{ C/D ratio } & \multicolumn{2}{c}{ Group (1) } & \multicolumn{2}{c}{ Group (2) } & \multicolumn{3}{c}{ Group (3) } & \multicolumn{2}{c}{ Total } \\
\cline { 2 - 9 } & No. & $\%$ & No. & $\%$ & No. & $\%$ & No. & $\%$ \\
\hline 0 & 16 & 72.7 & 19 & 21.8 & 10 & 3.66 & 45 & 11.8 \\
0.1 & 6 & 27.3 & 42 & 48.3 & 24 & 8.79 & 72 & 18.8 \\
0.2 & 0 & 0.0 & 17 & 19.5 & 215 & 78.8 & 232 & 60.7 \\
0.3 & 0 & 0.0 & 7 & 8.05 & 19 & 6.96 & 26 & 6.8 \\
0.4 & 0 & 0.0 & 1 & 1.15 & 2 & 0.73 & 3 & 0.8 \\
0.5 & 0 & 0.0 & 1 & 1.15 & 1 & 0.37 & 2 & 0.5 \\
0.6 & 0 & 0.0 & 0 & 0.00 & 1 & 0.37 & 1 & 0.3 \\
0.7 & 0 & 0.0 & 0 & 0.00 & 1 & 0.37 & 1 & 0.3 \\
Total & 22 & 5.76 & 87 & 22.8 & 273 & 71.5 & 382 & 100 \\
\hline
\end{tabular}


Table 3. Identification of $\mathbf{C} / \mathbf{D}$ ratio in the three studied groups.

\begin{tabular}{ccccccccccc}
\hline \multirow{2}{*}{ C/D ratio } & \multirow{2}{*}{ No. } & \multicolumn{2}{c}{ Normal C/D $\leq 0.2$} & \multicolumn{2}{c}{ Suspected C/D $=0.3$} & \multicolumn{2}{c}{ Abnormal C/D >0.3 } & \multicolumn{2}{c}{ Test of significance } \\
\cline { 3 - 10 } & & No. & $\%$ & No. & $\%$ & No. & $\%$ & Z-test & P value \\
\hline Group (1) & 22 & 22 & 100 & 0 & 0.00 & 0 & 0.00 & 0.133 & 0.412 \\
Group (2) & 87 & 78 & 89.7 & 7 & 8.05 & 2 & 2.30 & 0.352 & 0.045 \\
Group (3) & 273 & 249 & 91.2 & 19 & 6.96 & 5 & 1.83 & 0.399 & 0.022 \\
Total & 382 & 349 & 91.4 & 26 & 6.81 & 7 & 1.83 & 0.412 & 0.019 \\
\hline
\end{tabular}

Table 4. Asymmetry of C/D ratios between the two eyes in the studied groups.

\begin{tabular}{cccccccc}
\hline \multirow{2}{*}{ C/D ratio asymmetry } & \multirow{2}{*}{ Total No. } & \multicolumn{2}{c}{$0-0.1$} & \multicolumn{2}{c}{$\geq 0.2$} & \multicolumn{2}{c}{ Test of significance } \\
\cline { 3 - 8 } & & No. & $\%$ & No. & $\%$ & $\chi^{2}$ & P value \\
\hline Group (1) & 22 & 22 & 100 & 0 & 0.0 & 0.008 & 0.733 \\
Group (2) & 87 & 83 & 95.40 & 4 & 4.60 & 0.146 & 0.026 \\
Group (3) & 273 & 259 & 94.87 & 14 & 5.13 & 0.322 & 0.011 \\
Total & 382 & 364 & 95.29 & 18 & 4.71 & 0.387 & 0.009 \\
\hline
\end{tabular}

constitutes Group (3). Also, 47.6\% of them (182 children) were males, and $52.4 \%$ (200 patients) were female.

This study shows different $\mathrm{C} / \mathrm{D}$ ratios in each age group. It is observed that in Group (1), all infants showed normal $\mathrm{C} / \mathrm{D}$ ratio (i.e. $\mathrm{C} / \mathrm{D}$ equal to or less than 0.1 ).

In Group (2), most of the preschool children, 78 (89.7\%), had normal C/D ratios (i.e. C/D less than 0.2) and 7 of them (8\%) had suspected abnormal C/D ratio (i.e. $\mathrm{C} / \mathrm{D}=0.3$ ), this group showed two abnormal $\mathrm{C} / \mathrm{D}$ ratios, one was 0.4 and one was 0.5 (2.3\%).

Group (3) showed 249 out of 273 children (71.3\%) normal C/D ratios, 19 (6.96\%) had suspected abnormal $\mathrm{C} / \mathrm{D}$ ratios, while 5 children $(1.83 \%)$ had abnormal C/D ratios. The 5 abnormal children were two had $\mathrm{C} / \mathrm{D}$ ratio 0.4 , while $\mathrm{C} / \mathrm{D}$ ratios of $0.5,0.6$ and 0.7 were found in one child each. So the highest $\mathrm{C} / \mathrm{D}$ ratio found was one case had 0.7 in Group (3).

Premature birth was associated with the presence of a double ring. A low birth weight and low gestational age influence the form of the optic disc [3]. They found a significant negative correlation between the form of the optic disc and gestational age ( $\mathrm{P}=0.03$ ); $75 \%$ of optic discs showed a double ring and $89 \%$ had visible disc cupping.

Samarawickrama et al. [2] concluded that low birth weight, short birth length, and small head circumference at birth were associated with larger cup/disc ratio in children aged 12 years. Their findings suggest that fetal growth restriction could adversely influence optic nerve head parameters. This may have implications for future risk of glaucomatous optic neuropathy.

Suspected abnormal and abnormal C/D ratios in low age groups in not suggestive diagnosis of glacucoma, other diagnostic procedures must be performed as most cases had physiological cupping. Nowadays values of retinal nerve fiber layer (RNFL) thickness and optic nerve head $(\mathrm{ONH})$ parameters measured by OCT are more reliable [13].

Mezad-Koursh et al. [14] study 12 children with cup to disc ratio (0.75) in both eyes. Indications for neuroimaging included: premature birth, a congenital syndrome, and visual field defects. Neuroimaging was also performed in 3 cases of incidental enlarged optic nerve head excavation. Physiological cupping was diagnosed in 11 of the 12 cases (92\%). In only one case (8\%), periventricular leucomalacia was diagnosed after neuroimaging. No deterioration was observed in visual acuity or cup to disc ratio during a one year follow-up. They concluded that an incidental finding of enlarged optic disc head excavation, in the absence of a significant medical history and with a normal neuro-ophthalmologic examination, can be diagnosed as physiologic cupping and requires no further workup.

Asymmetry in optic disc appearance, especially cup/ disc ratio, is one criterion that helps to alert to the possibility of glaucoma [15].

Gupta et al. [16] stated that one-fourth of primary juvenile open angle glaucoma (JOAG) patients present as a unilateral optic neuropathy with $60 \%$ of these having normal IOP in the fellow eyes. Primary JOAG may present with considerable asymmetry with a small proportion presenting as a unilateral disease.

This study showed that all children in Group (1) showed asymmetry $<0.1$, while Group (2) showed 4 children out of 87 (4.6\%) had asymmetry > 0.2 and Group (3) showed 14 children out of 273 had asymmetry $(\mathrm{P}<0.05)$.

A cross-sectional analysis of $C / D$ was performed per year of age from 0 to 10 years and linear regression was used to compare C/D progression between preterm and 
term children and between low versus normal birth weight children [17]. They found that children exhibited progressive optic cupping. In term children, mean $\mathrm{C} / \mathrm{D}$ increased by 0.0075 per year. Rate of mean $\mathrm{C} / \mathrm{D}$ progression was double in children born preterm: $0.0160(\mathrm{P}=$ 0.049 , comparison to term) per age-year. A similar, nonsignificant trend is observed when comparing low birth weight to normal children $(\mathrm{P}=0.131)$. They concluded that prematurity and low birth weights are associated with increased rate of cupping in children. Clinicians should recognize that $\mathrm{C} / \mathrm{D}$ progression is not a specific sign of glaucoma in children.

The C/D ratio has several shortcomings. It only indirectly examines the neuroretinal rim tissue, concentrating on the width of the hole rather than the surrounding rim tissue that determine its border. Also, the examiner is focused on the ratio in the vertical disc axis and may overlook focal thinning in an oblique axis. The C/D ratio does not take into consideration the optic disc size [18].

Hence, large discs which are likely to have larger C/D ratio (but may have normal neuroretinal rims) are more likely to be classified as glaucomatous [19], while small discs with small C/D ratio are more likely to be classified as normal, whether they actually have glaucoma or not [20].

\section{Conclusion}

The present study provides novel normative data on C/D ratios in Egyptian preschool and school age children as well as infantile age for clinicians in practice.

\section{REFERENCES}

[1] M. Yoshida, E. Okada, N. Mizuki, et al., “Age-Specific Prevalence of Open-Angle Glaucoma and Its Relationship to Refraction among More than 60,000 asymptomatic Japanese subjects," Journal of Clinical Epidemiology, Vol. 54, No. 11, 2001, pp. 1151-1158. http://dx.doi.org/10.1016/S0895-4356(01)00388-2

[2] C. Samarawickrama, S. C. Huynh, G. Liew, G. Burlutsky and P. Mitchell, "Birth Weight and Optic Nerve Head Parameters,” Ophthalmology, Vol. 116, No. 6, 2009, pp. 1112-1118.

http://dx.doi.org/10.1016/j.ophtha.2008.12.061

[3] S. Hackl, F. Zeman, H. Helbig and I. M. Oberacher-Velten, “Optic Disc Morphology in Premature Infants,” British Journal of Ophthalmology, Vol. 97, No. 3, 2013, pp. 314-317. http://dx.doi.org/10.1136/bjophthalmol-2012-302066

[4] E. Z. Blumenthal, A. Haddad, A. Horani and I. Anteby, "The Reliability of Frequency-Doubling Perimetry in Young Children,” Ophthalmology, Vol. 111, No. 3, 2004, pp. 435-439. http://dx.doi.org/10.1016/j.ophtha.2003.06.018

[5] J. Morales, S. Al Shahwan, S. Al Odhayb, I. Al Jadaan and D. P. Edward, "Current Surgical Options for the
Management of Pediatric Glaucoma,” Journal of Ophthalmology, Vol. 2013, 2013, Article ID: 763735. http://dx.doi.org/10.1155/2013/763735

[6] E. McLoone, M. O’Keefe, V. Donoghue, S. McLoone, N. Horgan and B. Lanigan, "RetCam Image Analysis of Optic Disc Morphology in Premature Infants and Its Relation to Ischaemic Brain Injury,” British Journal of Ophthalmology, Vol. 90, No. 4, 2006, pp. 465-471. http://dx.doi.org/10.1136/bjo.2005.078519

[7] G. Zhou, “The C/D Ratio in Normal Newborns,” Zhonghua Yan Ke Za Zhi, Vol. 29, No. 2, 1993, pp. 105-107.

[8] M. Armaly and R. Sayeghi, “The Cup/Disk Ratio,” Archives of Ophthalmology, Vol. 82, No. 2, 1969, pp. 191196.

[9] W. J. Hart, M. Yablonski, M. Kass, et al., "Multivariate Analysis of the Risk of Glaucomatous Visual Field Loss," Archives of Ophthalmology, Vol. 97, No. 8, 1979, pp. 1455-1458.

[10] H. A. Quigley II, "Changes in the Appearance of the Optic Disc,” Survey of Ophthalmology, Vol. 30, No. 2, 1985, pp. 117-126.

[11] J. B. Jonas, A. M. Schmidt, J. A. Müller-Bergh, et al., "Human Optic Nerve Fiber Count and Optic Disc Size," Investigative Ophthalmology \& Visual Science, Vol. 33, No. 6, 1992, pp. 2012-2018.

[12] M. El-Dairi, S. Holgado, S. Asrani and S. F. Freedman, "Optical Coherence Tomography (OCT) Measurements in Black and White Children with Large Cup-to-Disc Ratios," Experimental Eye Research, Vol. 93, No. 3, 2011, pp. 299-307. http://dx.doi.org/10.1016/j.exer.2011.05.004

[13] N. Elía, V. Pueyo, I. Altemir, D. Oros and L. E. Pablo, "Normal Reference Ranges of Optical Coherence Tomography Parameters in Childhood," British Journal of Ophthalmology, Vol. 96, No. 5, 2012, pp. 665-670. http://dx.doi.org/10.1136/bjophthalmol-2011-300916

[14] D. Mezad-Koursh, I. Leibovitch, A. Loewenstein and S. Kurtz, "Enlarged Optic Nerve Head Excavation in Children,” Harefuah, Vol. 152, No. 2, 2013, pp. 69-72, 124.

[15] A Beck, "Evaluating and Managing Optic Disc Cupping in Children, How to Tell When a Child Has Glaucoma," Glaucoma Today, 2009, pp. 26-28.

http://bmctoday.net/glaucomatoday/pdfs/GT0109_06.pdf

[16] V. Gupta, S. Gupta, M. Dhawan, A. Sharma, K. S. Kapoor and R. Sihota, "Extent of Asymmetry and Unilaterality among Juvenile Onset Primary Open Angle Glaucoma Patients," Clinical \& Experimental Ophthalmology, Vol. 39, No. 7, 2011, pp. 633-638. http://dx.doi.org/10.1111/j.1442-9071.2011.02522.x

[17] H. J. Park, C. Hampp and J. L. Demer, "Longitudinal Study of Optic Cup Progression in Children," Journal of Pediatric Ophthalmology and Strabismus, Vol. 48, No. 3, 2011, pp. 151-156. http://dx.doi.org/10.3928/01913913-20100719-06

[18] H. V. Danesh-Meyer, B. J. Gaskin, T. Jayusundera, M. Donaldson and G. D. Gamble, "Comparison of Disc Damage Likelihood Scale, Cup to Disc Ratio, and Heidelberg Retina Tomograph in the Diagnosis of Glaucoma," British Journal of Ophthalmology, Vol. 90, No. 4, 2006, 
pp. 437-441.

http://dx.doi.org/10.1136/bjo.2005.077131

[19] J. B. Jonas, F. M. Zach, G. C. Gusek, et al., "Pseudoglaucomatous Physiologic Large Cups,” American Journal of
Ophthalmology, Vol. 107, 1989, pp. 137-144.

[20] A. Heijl and H. Molder, "Optic Disc Diameter Influences the Ability to Detect Glaucomatous Disc Damage,” Acta Ophthalmologica, Vol. 71, No. 1, 1993, pp. 122-129. 